\title{
Contabilidade Ambiental: Um Estudo sobre sua Aplicabilidade em Empresas Brasileiras
}

\author{
Adalto de Oliveira Santos \\ Graduando em Ciências Contábeis da PUC-Campinas \\ Fernando Benedito da Silva \\ Graduando em Ciências Contábeis da PUC-Campinas
}

Synval de Souza

Graduando em Ciências Contábeis da PUC-Campinas

Marcos Francisco Rodrigues de Sousa - Orientador

Professor Ms. da PUC-Campinas

RESUMO

A globalização da economia e a conscientização da sociedade estão forçando, atualmente, as empresas a adotarem uma postura responsável perante o meio ambiente, isto é, produzir sem agressão à natureza. Para isto elas estão implantando um Sistema de Gestão Ambiental de acordo com as normas da série ISO 14000.

Fazer este gerenciamento exige a aplicação de um considerável montante de recursos financeiros, devendo-se ter constante preocupação em controlá-los. Entende-se que a contabilidade é uma das ferramentas mais eficientes e eficazes para este processo.

Observa-se, no entanto, que poucas empresas, no Brasil, utilizam a contabilidade na sua gestão ambiental. Portanto, o principal objetivo da realização deste estudo é verificar qual o grau de desenvolvimento da Contabilidade Ambiental nas empresas brasileiras.

Após uma revisão bibliográfica sobre o tema, foi elaborada uma pesquisa de campo que consistiu no envio de um questionário aos departamentos de contabilidade de indústrias potencialmente poluidoras. $\mathrm{O}$ universo compreendeu as empresas listadas no guia "As 500 maiores empresas do Brasil", edição 2000, da revista Exame; e a amostra foi de 50 empresas cujo faturamento, em 2000, ultrapassou US $\$ 50$ biIhões.

Palavras-chave: gerenciamento ambiental, contabilidade, aplicação, empresas brasileiras.
ABSTRACT

The globalization of the economy and the awareness of the society are forcing, currently, the companies to adopt a responsible position before the environment, that is, to produce without aggression the nature. For this they are implanting a System of Environmental Management in accordance with the norms of series ISO 14000.

To make this management demands the application of a considerable sum of financial features, having itself to have constant preoccupation in controlling them. One understands that the accounting is one of the efficient tools most for this process.

It is observed, however, that few companies, in Brazil, use the accounting in its environmental management. Therefore, the main objective of the accomplishment of this study is to verify which the degree of development of the Environmental Accounting in the Brazilian companies.

After a bibliographical walk through on the subject, was elaborated a field research that consisted of the sending of a questionnaire to the accounts departements of potentially polluting industries. The universe understood the companies listed in the guide "500 bigger companies of Brazil", edition 2000, of the Exame Maganize, and the sample was of 50 companies whose invoicing, in 2000 , exceed US $\$ 50$ billion.

Key words: environmental management, accounting, application, Brazilian companies. 


\section{1 - INTRODUÇÃO}

Nos últimos anos vem aumentando a pressão, exercida pela sociedade, sobre as empresas que não respeitam o meio ambiente. Por esta razão, aliada a exigência do mercado, estas empresas estão sendo obrigadas a adotar uma política de controle, preservação e recuperação ambiental a fim de garantir sua continuidade.

Na visão de Barbieri (1997, p. 199): “ O crescimento da consciência ambiental, ao modificar os padrões de consumo, constitui uma da mais importantes armas em defesa do meio ambiente. Quando a empresa busca capturar oportunidades através do crescente contingente de consumidores responsáveis através de ações legítimas e verdadeiras, essas ações tendem a reforçar ainda mais a consciência ambiental, criando um círculo virtuoso, na qual a atuação mercadológica, marketing verde, como querem alguns, torna-se um instrumento de educação ambiental."

O modelo mais usado pelas entidades para atingir este objetivo foi a implantação de uma gestão ambiental, isto é, método pelo qual elas controlam o impacto de suas atividades produtivas sobre o meio ambiente.

Fazer este gerenciamento ambiental exige colaboração dos diversos departamentos da Companhia. Tem que haver interação entre a administração e produção, garantindo, assim, a eficácia do processo.

Segundo Epelbaum (1997, p. 235): "Pode-se expressar sucintamente o comprometimento com o meio ambiente como sendo a contínua intencionalidade e prática em considerar a proteção ambiental nas decisões gerenciais e operacionais cotidianas. Tal noção de comprometimento, para ser considerada abrangente dentro das organizações, deve ser adotada por todos os seus níveis e funções, desde a alta administração até o nível operacional."

A contabilidade é considerada uma poderosa ferramenta para este processo, mas o que se verifica na atual conjuntura das empresas brasileiras é um baixo grau de conhecimento e aplicação da contabilidade ambiental. Esta questão será analisada a partir da elaboração de um panorama da atual situação da contabilidade no gerenciamento ambiental das companhias.

\section{2 - PLANEJAMENTO DA PESQUISA}

\section{1 - Formulação do Problema}

Muito se tem discutido sobre qual a melhor forma das empresas conciliarem seus processos produtivos com a questão ambiental. Em resposta a esta necessidade surgiram normas e processos que, através de um Sistema de Gestão Ambiental, as auxiliaram no controle do impacto causado pelas suas atividades no meio ambiente.

$\mathrm{Na}$ análise de Sanches (1997, p.54): "O enfoque da proteção ambiental, desloca, então, a dimensão ambiental do âmbito da função de produção para se tornar parte da função da administração. Esse reposicionamento, enfim, determina uma nova relação empresa - meio ambiente na medida em que os fatores ambientais são incorporados nas metas, políticas e estratégias da empresa e a proteção ambiental passa a fazer parte de seus objetivos de negócios."

Entende-se, portanto, que a Contabilidade pode auxiliar os administradores no gerenciamento empresarial do meio ambiente, pois ela é considerada, atualmente, uma das principais ferramentas de gestão de negócios.

Segundo Ribeiro (1992, p.56): "A contabilidade, enquanto instrumento de comunicação entre empresas e sociedades, poderá estar inserida na causa ambiental. A avaliação patrimonial, considerando os riscos e benefícios ambientais inerentes às peculiaridades de cada atividade econômica, bem como sua localização, poderá conscientizar os diversos segmentos de usuários das demonstrações contábeis sobre a conduta administrativa e operacional da empresa, no que tange $o$ empenho da empresa sobre a questão."

Este estudo parte da premissa de que poucas entidades no Brasil utilizam a contabilidade em auxílio à gestão ambiental. Portanto, o problema que será alvo de investigação é saber qual o nível de desenvolvimento da contabilidade ambiental nas empresas brasileiras.

\section{2 - Procedimentos Metodológicos}

A metodologia utilizada para realização desta pesquisa consistiu numa revisão da bibliografia até então disponível no meio acadêmico. A seguir elaborouse uma pesquisa de campo, a qual foi constituída de um questionário enviado aos Departamentos de Contabilidade de diversas empresas. 
O universo deste estudo compreendeu as indústrias de setores potencialmente poluidores as quais faziam parte do Guia "As 500 Maiores Empresas do Brasil" da Revista Exame, edição 2000.

O contato foi feito, via e-mail, durante os meses de junho e julho de 2000, com 250 empresas e destas 50 responderam o questionário. Portanto a amostra foi de 50 empresas de grande porte cujo faturamento conjunto em 2000 ultrapassou a marca de US\$ 50 biIhões.

\section{3 - CONTABILIDADE AMBIENTAL}

\section{1 - Conceitos}

A contabilidade, uma das ciências mais antigas do mundo, originou-se com o intuito de quantificar a riqueza humana, ou seja, o patrimônio.

Ao longo dos séculos ela vem acompanhando a evolução da economia e criando novas técnicas de identificação, mensuração e evidenciação dos eventos econômicos e financeiros os quais causam mutações patrimoniais.

Atualmente, a contabilidade é considerada um sistema de informações que tem como objetivo auxiliar o gerenciamento das entidades para que estas possam garantir sua continuidade. Para Marion e ludícibus (2000, p. 53): "O objetivo da contabilidade pode ser estabelecido como sendo o de fornecer informação estruturada de natureza econômica, financeira e, subsidiariamente, física, de produtividade e social, aos usuários internos e externos à entidade objeto da Contabilidade."

A partir deste contexto, pode-se definir contabilidade ambiental como o estudo do patrimônio ambiental (bens, direitos e obrigações ambientais) das entidades. Seu objetivo é fornecer aos seus usuários, interno e externo, informações sobre os eventos ambientais que causam modificações na situação patrimonial, bem como realizar sua identificação, mensuração e evidenciação.

$\mathrm{Na}$ avaliação de Martins e De Luca (1994, p.25): "As informações a serem divulgadas pela contabilidade vão desde os investimentos realizados, seja em nível de aquisição de bens permanentes de proteção a danos ecológicos, de despesas de manutenção ou correção de efeitos ambientais do exercício em curso, de obrigações contraídas em prol do meio ambien- te, e até de medidas físicas, quantitativas e qualitativas, empreendidas para sua recuperação e preservação."

Teoricamente parece ser fácil seu entendimento e sua aplicação, mas na prática são encontradas várias dificuldades as quais impedem o seu uso. A principal delas é a segregação das informações de natureza ambiental das demais informações gerais da empresa, bem como sua correta classificação e avaliação contábil.

Bergamini Júnior (1999, p.4) enumera outros fatores que dificultam o processo de implementação da contabilidade ambiental:

> Ausência de definição clara de custos ambientais;

> Dificuldade em calcular um passivo ambiental efetivo;

> Problema em determinar a existência de uma obrigação no futuro por conta de custos passados;

> Falta de clareza no tratamento a ser dado aos "ativos de vida longa", como por exemplo no caso de uma usina nuclear;

> Reduzida transparência com relação aos danos provocados pela empresa em seus ativos próprios, dentre outros.

Apesar das dificuldades, este trabalho procura mostrar de maneira simples os principais conceitos da contabilidade ambiental.

\subsection{1 - Ativo Ambiental}

São considerados ativos ambientais todos os bens e direitos destinados ou provenientes da atividade de gerenciamento ambiental, podendo estar na forma de capital circulante ou capital fixo.

O capital circulante (capital de giro) é o montante aplicado para a realização da atividade econômica da empresa, sendo composto pelas disponibilidades e pelos ativos realizáveis a curto e longo prazo. Exemplos de ativos ambientais que se enquadram neste grupo:

a) na conta disponibilidades podem ser contabilizados os valores referentes a recebimentos oriundos de uma receita ambiental;

b) nos ativos realizáveis a curto e longo pra- 
zo podem ser lançados os direitos originários de uma receita ambiental e os estoques, quando relacionados com insumos do sistema de gerenciamento ambiental ou com produtos reaproveitados do processo operacional.

No capital fixo as contas ambientais podem ser divididas em:

a) Investimentos: participação societária em empresas ecologicamente responsáveis;

b) Imobilizado: bens destinados a manutenção do gerenciamento ambiental, por exemplo, filtros de ar, equipamentos da estação de tratamento de efluentes, etc.;

c) Diferido: gastos em desenvolvimento de tecnologia "limpa" de produção que beneficiarão exercícios futuros, como por exemplo, os gastos de implantação do Sistema de Gestão Ambiental para a certificação ISO 14001.

Para completar o grupo do ativo, vale destacar, também, o ativo ambiental intangível que são bens ou direitos incorpóreos de difícil mensuração. Como exemplo, pode-se citar a certificação ISO 14001 que trará valorização da imagem e marca da empresa.

\subsection{2 - Passivo Ambiental}

Passivo ambiental é toda obrigação contraída voluntária ou involuntariamente destinada a aplicação em ações de controle, preservação e recuperação do meio ambiente, originando, como contrapartida, um ativo ou custo ambiental.

Na opinião do IBRACON (1996, p.5): "O passivo ambiental pode ser conceituado como toda agressão que se praticou/pratica contra o meio ambiente e consiste no valor de investimentos necessários para reabilitá-lo, bem como multas e indenizações em potencial."

De acordo com a IAS $37^{1}$, para o reconhecimento de um passivo ambiental deve-se atender os seguintes requisitos (apud FERREIRA, 2000, p.115):

1) O primeiro deles é de que a entidade tem uma obrigação presente legal ou implícita como conseqüência de um evento passado, que é o uso do meio ambiente (água, solo, ar) ou a geração de resíduos tóxicos.

2) O segundo requisito é o de que é (sic!) provável que recursos sejam exigidos para se liquidar o passivo ambiental, ou seja, a chance de ocorrer a saída de recursos, o que depende de um ou mais eventos futuros, é maior do que a de não ocorrer.

3) O terceiro requisito é o de que o montante do passivo ambiental envolvido possa ser estimado com suficiente segurança.

O passivo ambiental, como qualquer passivo, está dividido em capital de terceiros e capital próprio os quais constituem as origens de recursos da entidade.

Exemplos de origens:

a) Bancos - empréstimos de instituições financeiras para investimento na gestão ambiental;

b) Fornecedores - compra de equipamentos e insumos para o controle ambiental;

c) Governo - multas decorrentes a infração ambiental;

d) Funcionários - remuneração de mão de obra especializada em gestão ambiental;

e) Sociedade - indenizações ambientais;

f) Acionistas - aumento do capital com destinação exclusiva para investimentos em meio ambiente ou para pagamento de um passivo ambiental;

g) Entidade - através de destinação de parte dos resultados (lucro) em programas ambientais.

\subsection{3 - Receita Ambiental}

Segundo o IASB (apud IUDÍCIBUS \& MARION, 2000, p.173) a receita pode ser definida como: “(...) 0 acréscimo de benefícios econômicos durante o período contábil na forma de entrada de ativos ou decréscimo de exigibilidade e que redunda num acréscimo do patrimônio líquido, outro que não o relacionado a ajustes de capital (...)"

O objetivo principal da implantação da gestão ambiental não é gerar receita para a empresa, e sim, desenvolver uma política responsável acerca dos problemas ambientais. Mas isto não impede que a empresa tire algum proveito econômico deste processo. A seguir têm-se três exemplos de receitas ambientais: 
Prestação de serviços especializados em gestão ambiental;

- Venda de produtos elaborados a partir de sobras de insumos do processo produtivo;

> Participaçãonofaturamentototaldaempresaque se reconhece como sendo devida a sua atuação responsável com o meio ambiente.

Este último exemplo, apesar de sua complexidade, pode ser calculado tomando como base estatísticas elaboradas com o mercado consumidor, determinando-se o percentual de clientes que realizaram a compra tendo como exigência e pré condição o item responsabilidade ambiental. Corroborando esta idéia, Martins e Ribeiro (1995, p.35) considera que: "A maciça conscientização da sociedade em muitos lugares veio afetar a imagem da empresa junto ao seu público consumidor, o qual passou a ser forte elemento de pressão para as empresas começarem a investir no controle ambiental, visto que dele depende a evolução do fluxo de receitas da empresa."

\subsection{4 - Custos e Despesas Ambientais}

Custos e despesas ambientais são gastos (consumo de ativos) aplicados direta ou indiretamente no sistema de gerenciamento ambiental do processo produtivo e em atividades ecológicas da empresa. Quando aplicados diretamente na produção, estes gastos são classificados como custo, e se forem aplicados de forma indireta são chamados de despesa.

$\mathrm{Na}$ visão de Ribeiro (1992, p.80): "O valor dos insumos, mão de obra, amortização de equipamentos e instalações do processo de preservação, proteção e recuperação do meio ambiente, bem como serviços externos e os gastos para realização de estudos técnicos sobre a metodologia e procedimentos adequados podem constituir-se em exemplos de custos e despesas ambientais."

É importante ressaltar, também, que os custos ambientais podem ser classificados como custos in- ternos (privados) e custos externos (sociais).

Custos internos são aqueles tradicionais contabilizados ao longo do processo produtivo os quais servem de base para a determinação do preço de venda dos produtos. Exemplo: matéria prima, mão-de-obra, depreciação de equipamentos, etc. Geralmente as empresas não encontram maiores dificuldades em identificá-los e controlá-los.

Custos externos, de acordo com a U.S. EPA² (1995, p.34), são aqueles custos gerados pelo impacto da atividade da empresa no meio ambiente e na sociedade, os quais a companhia não se responsabiliza financeiramente. Exemplo: custo com tratamento de doenças respiratórias ocasionadas pela poluição do ar.

Segundo Martins e Ribeiro (1995, p.31): "Nunca se imputou, e ainda não se imputa à mercadoria produzida, todos os custos necessários à sua elaboração, pois a empresa agrega ao seu custo de produção somente o valor de insumos que representam desembolso financeiro por parte da empresa, ou seja, aqueles pelos quais efetivamente ela paga. Não são computados gastos futuros que a sociedade terá para repor esses bens, menos ainda o quanto a sociedade futura sofrerá para não tê-los a disposição, quando não renováveis."

A identificação e mensuração dos custos sociais são consideradas um dos principais desafios, atualmente, para a Ciência Contábil, por isso devem ser objeto de estudos mais aprofundados.

\section{2 - Aplicações}

A contabilidade ambiental possui um grande potencial de aplicação dentro de um sistema contábil, seja ele público ou privado. Atenta às particularidades de cada usuário ela procura fornecer informações que atendam suas necessidades.

A Agência de Proteção Ambiental dos EUA elaborou um quadro destacando as principais aplicações da contabilidade ambiental (1995, p.4):

\begin{tabular}{|l|c|c|}
\hline APLICAÇÃo & FOCO & USUÁRIO \\
\hline Contabilidade Nacional & Nação & Externo \\
\hline Contabilidade Financeira & Empresa & Externo \\
\hline Contabilidade Gerencial & Empresa & Interno \\
\hline
\end{tabular}

\footnotetext{
${ }^{2}$ Agência de Proteção Ambiental dos Estados Unidos
} 


\subsection{1 - Contabilidade Nacional}

Contabilidade Nacional é um instrumento que mensura as atividades macroeconômicas de um país, ou seja, é utilizada para medir monetariamente o valor total da produção em determinado período, formando o chamado Produto Interno Bruto (PIB).

No contexto ambiental, este tipo de contabilidade pode ser aplicada para avaliar as reservas e o consumo de recursos naturais renováveis e não-renováveis. Todavia alguns estudiosos apontam limitações e faIhas no atual sistema de contas nacionais, principalmente no que se refere ao cálculo do PIB.

O economista equatoriano Alberto Acosta destaca que certas atividades que agridem o meio ambiente são somadas no montante do PIB, quando deveriam ser subtraídas. Um exemplo disto é a exploração do petróleo a qual é considerada um indicador de riqueza nacional, mas sabe-se que a cada barril explorado diminui-se suas reversas, ficando assim o país "mais pobre" em petróleo. Segundo Acosta (2000): “(...) como que uma atividade que diminui nosso patrimônio natural ou que nos obriga a gastar com recuperação ou proteção pode se apresentar como elemento de crescimento do PIB?"

O jornalista Washington Novaes apresenta outros exemplos da limitação da contabilidade ambiental no contexto nacional. Segundo ele (2001, p.A2): “(...) quem contabiliza, na área de saúde, os custos de poluição atmosférica gerada pelos gases emitidos por veículos? Quem soma os investimentos necessários para implantar e conservar as redes viárias e os debita proporcionalmente na conta de automóveis? Quem responsabiliza a agricultura pelos custos dos modelos de ocupação do solo-erosão e perda de fertilidade, degradação de bacias hidrográficas, êxodo rural e inchaço das periferias urbanas, etc. ?"

Como pode-se observar esta não é uma tarefa simples, por isso deve haver uma maior preocupação dos governos em incentivar o desenvolvimento de novas metodologias que traduzam com mais exatidão o nível de consumo e esgotamento dos recursos naturais existentes no planeta, bem como o impacto causado pelas atividades econômicas no meio ambiente.

\subsection{2 - Contabilidade Financeira}

De acordo com ludícibus e Marion (2000, p.44): "Contabilidade Financeira é a contabilidade geral, necessária a todas empresas. Fornece informações bá- sicas aos seus usuários e é obrigatória conforme a legislação comercial."

Sua aplicação na área ambiental destina-se ao registro dos eventos relacionados ao meio ambiente como por exemplo a evidenciação de ativos e passivos ambientais nas demonstrações contábeis. Este tipo de informação esta sendo cada vez mais exigido pelo mercado, por isso é necessária a sua divulgação de maneira transparente e fidedigna.

O relatório que se mostra mais eficaz para esta demonstração é o Balanço Social o qual já é utilizado por várias empresas no Brasil. Todavia é importante que haja uma padronização dos modelos publicados atualmente.

\subsection{3 - Contabilidade Gerencial}

Destina-se à coleta e análise das informações fornecidas pela Contabilidade Financeira e Contabilidade de Custos com o objetivo de subsidiar o processo de tomada de decisões empresariais. A vantagem é que ela não está amarrada aos princípios contábeis e às legislações comercial e fiscal.

A Contabilidade Gerencial é a que melhor se aplica, dentre as anteriores, na gestão ambiental pois para gerir o meio ambiente é necessário um controle financeiro constante a fim de otimizar o resultado da política ambiental. Para Ferreira (1999, p.2): "De modo geral, a gestão contemporânea é movida a resultados, portanto, um sistema de informações voltado para a atividade ambiental deveria ter a capacidade de apresentar os resultados das ações referentes a ela e não somente em relação aos custos incorridos."

Um dos principais inibidores da falta de investimentos na gestão ambiental é a escassez de recursos das entidades. Portanto, a contabilidade se torna relevante através de suas informações as quais auxiliarão os gestores ambientais a desenvolverem um bom trabalho de monitoramento, proteção e recuperação do meio ambiente.

\section{4 - RESULTADO DA PESQUISA DE CAMPO}

A pesquisa de campo foi realizada durante os meses de junho e julho de 2000 e consistiu no envio, via e-mail, de um questionário para os Departamentos de Contabilidade de empresas listadas no Guia "500 Maiores Empresas do Brasil” da Revista Exame. No 
presente resultado estão contidas as respostas de 50 companhias que constituíram a amostragem deste estudo.

\section{Questão 01 - Enquadramento jurídico da empresa}

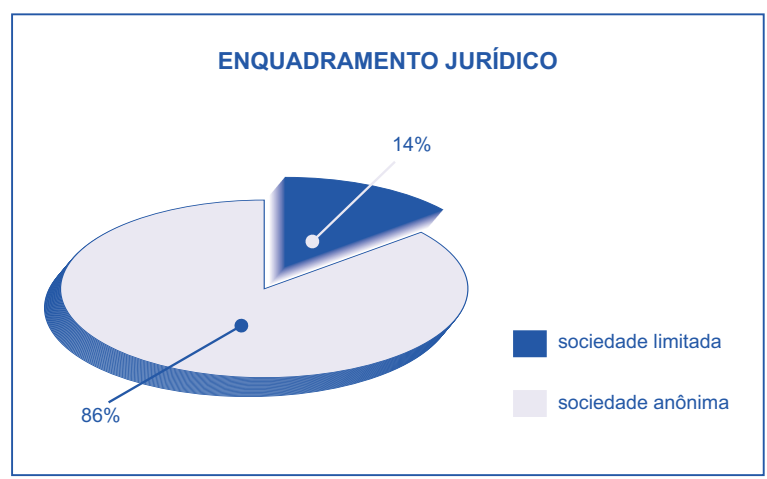

De acordo com o enquadramento jurídico, $86 \%$ das empresas que responderam o questionário são Sociedades Anônimas, enquanto 14\% Sociedades por Cotas de Responsabilidade Limitada.

\section{Questão 02 - Controle do capital aplicado na empresa}

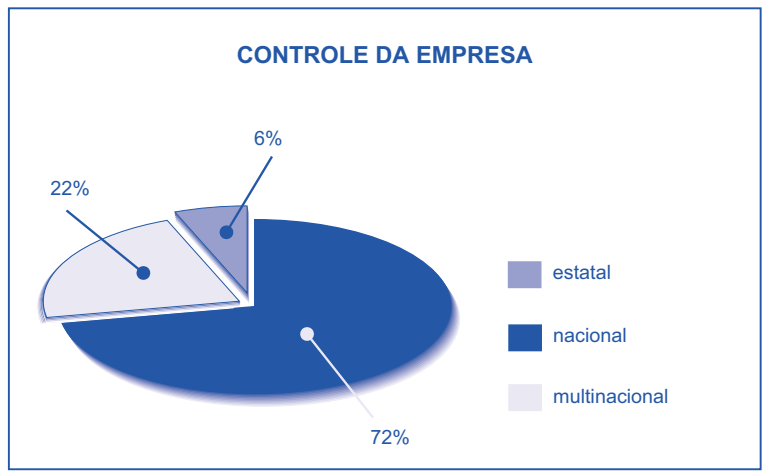

Quanto ao controle do capital, 6\% das empresas tem controle estatal, $72 \%$ privado nacional, enquanto em $22 \%$ predomina o capital internacional.

\section{Questão 03 - Certificação ISO 14001}

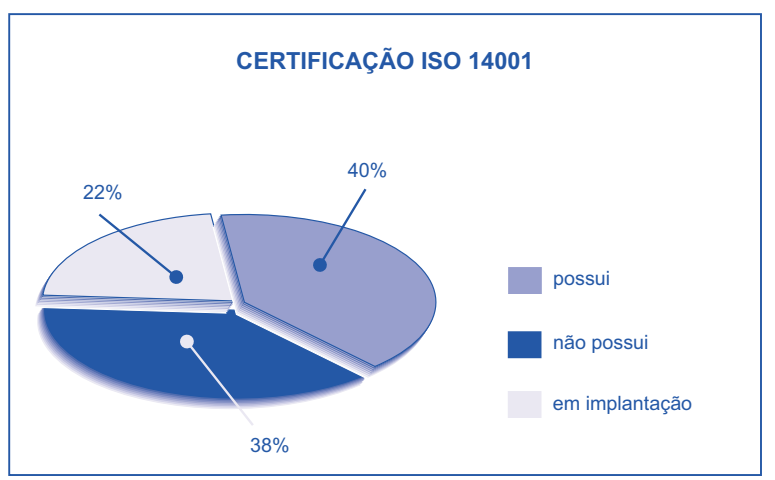

Questionadas sobre a posse da certificação ambiental ISO 14001, 40\% das companhias afirmaram terem o certificado, $38 \%$ ainda não e outros $22 \%$ estão implantando-a.

Separando-se esta questão de acordo com o controle do capital, tem-se o seguinte resultado:
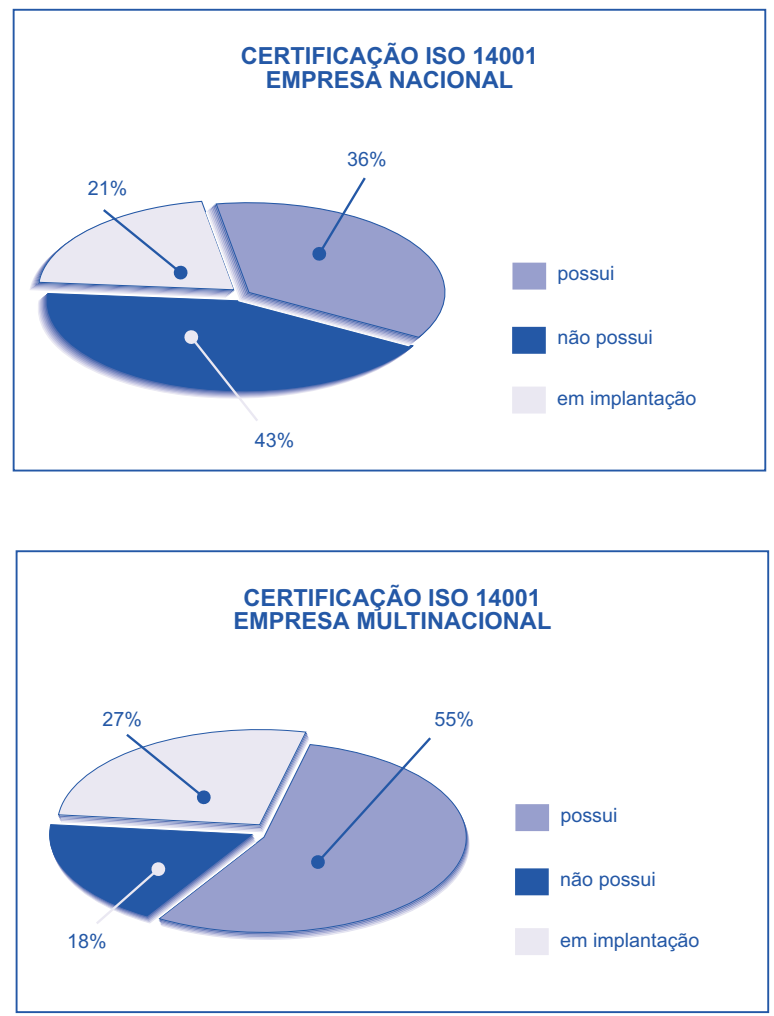

Nota-se que as multinacionais estão mais bem desenvolvidas nesta questão, pois o percentual de empresas que possuem ou estão implantando a ISO 14001 chega a 82\%; em contrapartida este número não passa de $57 \%$ entre as nacionais.

O melhor desempenho entre as companhias multinacionais deve-se ao fato de elas terem tecnologia mais avançada e recursos financeiros disponíveis para implantação do sistema. Além disso, em seus países de origem, a sociedade é extremamente exigente quando se trata da questão ambiental, obrigando, desta maneira, os empresários terem uma boa conduta com o meio ambiente, sob pena de boicote de seus produtos.

Todavia, vem crescendo o número de certificações entre as empresas nacionais. Os dois principais motivos conhecidos para este crescimento são a exigência do mercado externo e a conscientização da sociedade brasileira. 


\section{Questão 04 - Principal resultado alcançado pela empresa após a conquista da ISO 14001}

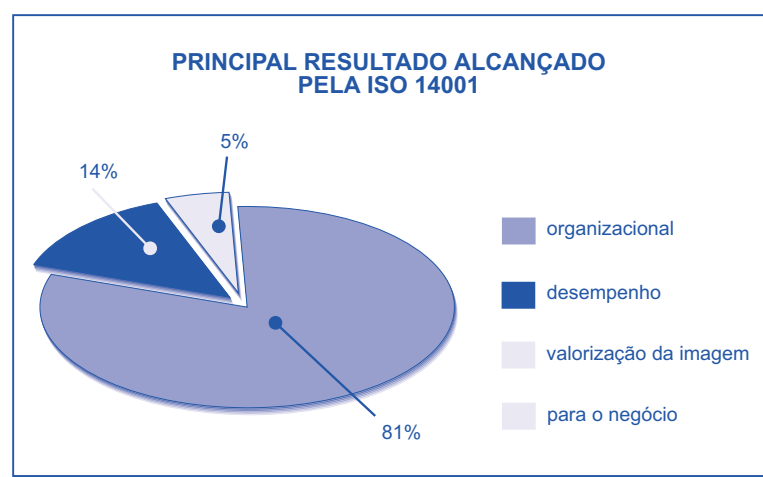

Das empresas que possuem a certificação ISO $14001,81 \%$ disseram que o principal resultado alcançado após a certificação foi organizacional, isto é, estruturação de uma política ambiental interna (planejamento, prevenção, comunicação, conscientização e comprometimento); outros $14 \%$ responderam que foi a melhoria no desempenho operacional (redução do consumo de água e energia, gerenciamento de resíduos) e para $5 \%$ o resultado mais importante foi a abertura para a comunidade e valorização da imagem institucional.

Surpreendentemente, não houve nenhuma resposta na alternativa em que apontasse melhoria nos negócios (aumento do faturamento, lucratividade e competitividade). Isto deve-se a falta de mensuração dos resultados alcançados pela gestão ambiental. Este tópico pela sua complexidade não é muito abordado no ambiente empresarial. Há, portanto, a necessidade de se criarem meios que pelo menos minimize esta dificuldade, procurando identificar, desta forma, qual o retorno financeiro que a implantação da ISO 14001 traz às empresas.

\section{Questão 05 - Aplicação da contabilidade ambiental}

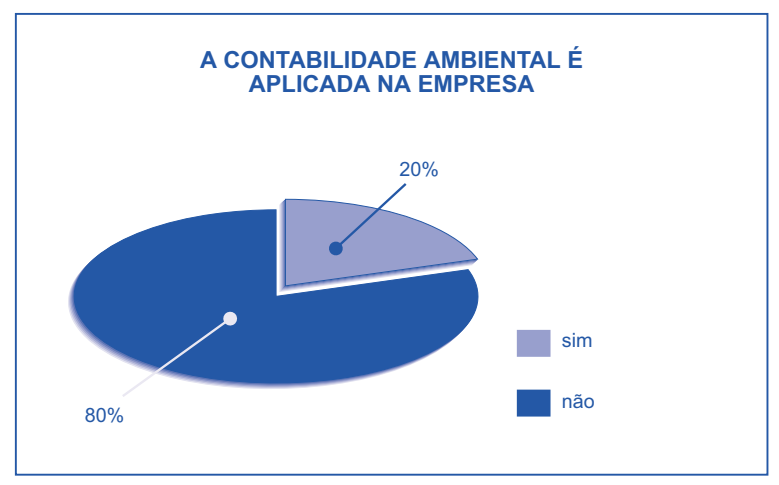

Esta é uma das principais questões da pesquisa, pois através dela pretende-se ter uma visão de como está a disseminação e desenvolvimento da contabilidade ambiental entre o empresariado brasileiro.

Verificou-se que apenas $20 \%$ das empresas utilizam a contabilidade em sua gestão ambiental, enquanto o restante (80\%) não a aplicam, comprovando desta maneira a hipótese levantada de que a maioria das companhias ainda desconhece as vantagens que a utilização da contabilidade ambiental pode trazer para seus negócios.

Considerando-se a origem do capital, tem-se o seguinte quadro:
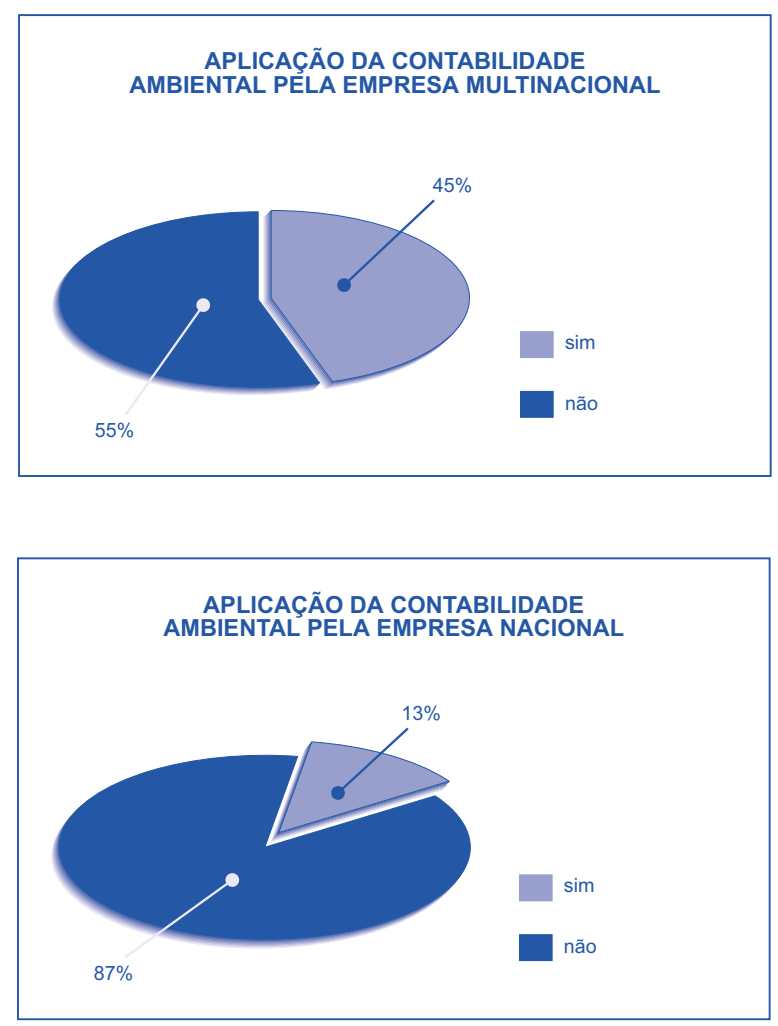

Verificou-se que $45 \%$ das multinacionais utilizam a contabilidade; já entre as nacionais este índice é de apenas $13 \%$.

Acredita-se que as empresas estrangeiras saíramse melhor porque elas já possuem experiências em seus países de origem, onde há um maior desenvolvimento da contabilidade ambiental. No Brasil, infelizmente, os gestores ainda não perceberam o potencial que a contabilidade possui para auxiliá-los no gerenciamento ambiental.

Todavia, recomenda-se um estudo mais amplo para saber quais os principais fatores que levam a esta diferença nos índices de aplicação da contabili- 
dade ambiental entre as empresas de capital nacional e as de capital internacional.

\section{Questão 06 - Conhecimentos sobre contabilidade ambiental}

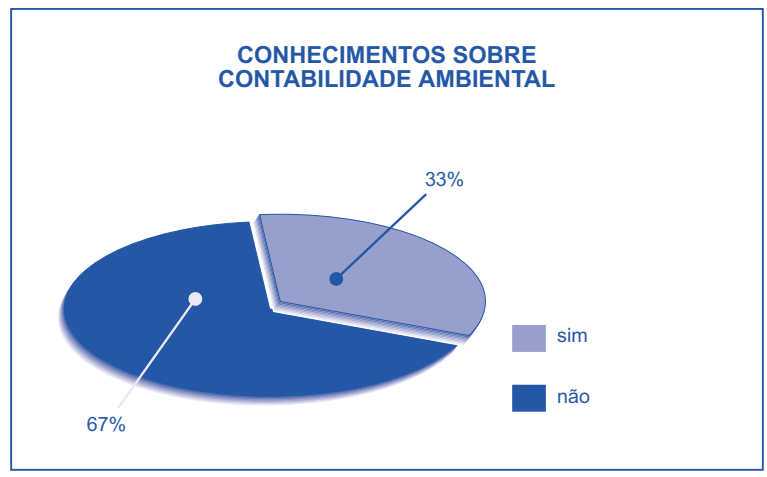

Questionadas a respeito de possuírem conhecimentos sobre contabilidade ambiental, 33\% das empresas responderam sim e $67 \%$ não. Se de um lado, este resultado é ruim mostrando o atraso do Brasil em relação a outros países; de outro é um incentivo a todos profissionais da área contábil, pois é uma nova oportunidade de trabalho que o mercado lhes oferece.

Ao relacionar esta questão com a anterior, podese concluir que o baixo índice de aplicação da contabilidade ambiental (20\%) deve-se a falta de informação sobre este tema, pois é muito baixo o nível de conhecimento das empresas. Espera-se que a partir do momento que a contabilidade ambiental seja mais difundida no país, ela possa ser amplamente utilizada.

\section{Questão 07 - Motivos para o desconhecimento da contabilidade ambiental}

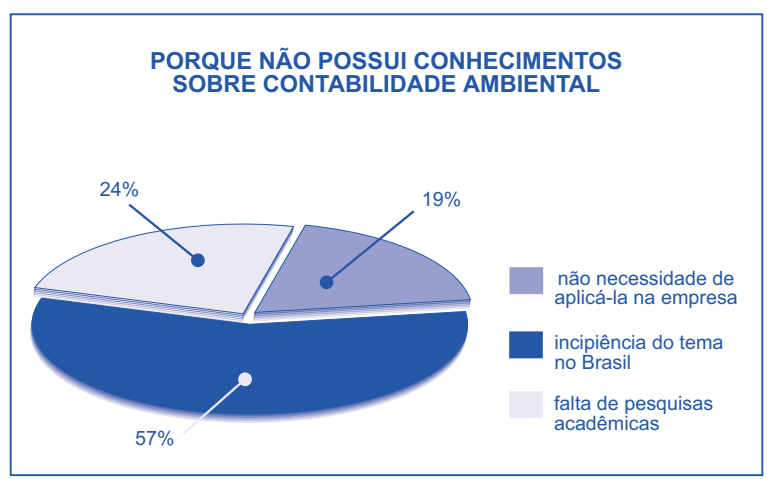

Dentre os principais motivos de desconhecimento, $57 \%$ das empresas destacaram como sendo a incipiência do tema no Brasil; para $24 \%$ o principal motivo é a falta de pesquisas acadêmicas e para 19\% a não necessidade de aplicação na empresa.

Este resultado mostra que é preciso o desenvolvimento de estudos científicos sobre contabilidade ambiental com participação conjunta de universidade e empresa. Somente assim conseguir-se-á avançar neste campo, demonstrando os benefícios que a utilização da contabilidade traz ao gerenciamento ambiental.

\section{Questão 8 - Contabilização dos gastos de implantação da ISO 14001}

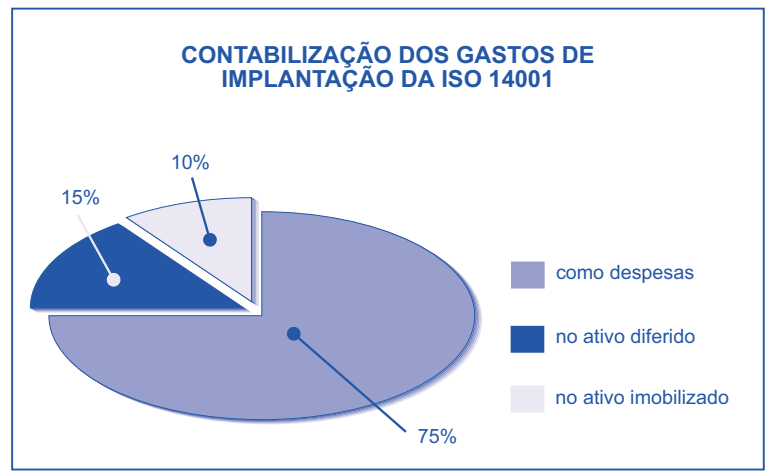

Observa-se, neste gráfico, que $75 \%$ das empresas certificadas com a ISO 14001 contabilizaram os gastos de sua implantação diretamente como despesas, afetando o resultado do respectivo exercício. Já $15 \%$ optaram em lançá-los no ativo diferido com o objetivo de amortização do volume total dos gastos em mais de um exercício. Por fim, $10 \%$ contabilizaram no ativo imobilizado, resultado que deve-se ao reconhecimento por parte das empresas somente dos gastos em instalações e equipamentos físicos, contas que poderiam ser imobilizadas.

\section{5 - CONCLUSÃO}

O Brasil está enfrentando sérios problemas ambientais. Para resolvê-los ou pelo menos amenizálos há a necessidade de uma união entre o poder público, o setor empresarial e a sociedade civil a fim de que juntos possam discutir a atual situação do meio ambiente, e o mais importante, atribuir as responsabilidades de cada um neste processo.

Nesta pesquisa foi estudada a atuação ambiental das empresas instaladas no país. Percebeu-se que a maior parte delas, principalmente os grandes grupos, 
está cada vez mais agindo de maneira responsável com questões ligadas ao meio ambiente. Os principais motivos para esta prática são a exigência do mercado, tanto interno como externo, e a conscientização da sociedade brasileira.

A implementação das normas da série ISO 14000 acarretou na diminuição do impacto causado pelos processos produtivos na natureza através de ações constantes de monitoramento ambiental.

Para a conquista e manutenção do certificado ISO 14001 são necessários investimentos consideráveis em equipamentos, mão-de-obra especializada, consultorias, dentre outros; que devem ser alvo de intenso controle financeiro com o objetivo de otimizar a utilização dos recursos empregados.

Uma das formas encontradas para atender este propósito foi o uso da contabilidade no Sistema de Gestão Ambiental. Entende-se que a Contabilidade Ambiental possui potencial para auxiliar os gestores nesta tarefa. Basicamente ela pode ser usada para demonstrar a responsabilidade ambiental da empresa, através da utilização dos relatórios contábeis onde deverão ser evidenciados, de forma transparente e fi- dedigna, os gastos com o controle ambiental. Também pode ser aplicada como instrumento de subsídio no processo de tomada de decisão utilizando-se de ferramentas da Contabilidade Gerencial e da Contabilidade de Custos.

Observou-se, no entanto, que a maioria das empresas ainda desconhece os benefícios da utilização da Contabilidade Ambiental. O estudo constatou que apenas $1 / 5$ das empresas pesquisadas aplicam-na em sua gestão. Vale destacar que considerando-se a origem do controle do capital este índice é de $45 \%$ entre as companhias multinacionais e de $13 \%$ entre as nacionais. Já entre os principais motivos apontados pelo baixo grau de conhecimento sobre Contabilidade Ambiental, 57\% das empresas indicaram a incipiência do tema no Brasil; $24 \%$ a falta de pesquisas acadêmicas; e 19\% a não necessidade de aplicá-la.

Conclui-se, portanto, que é imprescindível a união entre empresas e universidades no intuito de se aprofundar o desenvolvimento de pesquisas sobre Contabilidade Ambiental. Este trabalho procurou dar uma contribuição, agora espera-se que novos estudos a partir deste sejam realizados.

\section{REFERÊNCIAS BIBLIOGRÁFICAS}

ACOSTA, Alberto. O PIB mente? Seção de artigos www.ambienteglobal.com.br

BARBIERI, José Carlos. Competitividade Internacional e Normalização Ambiental. In Anais IV Encontro Nacional sobre Gestão Empresarial e Meio Ambiente, São Paulo, nov. 1997.

BERGAMINI JÚNIOR, Sebastião. Contabilidade e riscos ambientais. Revista do BNDES, Rio de Janeiro: v.6, n.11, junho de 1999.

CALLENBACH, Ernest e outros. Gerenciamento Ecológico. São Paulo: Ed. Cultrix, 1995.

CARVALHO, Nelson. Contabilidade e Ecologia: uma exigência que se impõe. Revista Brasileira de Contabilidade. Brasília: CFC, ano 20, ำ 75, abr/ jun 1991.

DONAIRE, Denis. Gestão ambiental na Empresa. São Paulo: Atlas, 1995.

EPELBAUM, Michel. Sistemas de Gestão Ambiental ISO 14000: mudando a postura reativa. In Anais
IV Encontro Nacional sobre Gestão Empresarial e Meio Ambiente, São Paulo, nov. 1997.

FERREIRA, Aracéli Cristina de Sousa. Contabilidade de custos para gestão do meio ambiente. Revista Brasileira de Contabilidade. Brasília: CFC, v. 25, no 101, set/out 1996.

FERREIRA, Aracéli Cristina de Sousa. Custos ambientais - uma visão de sistema de informações. VI Congresso Brasileiro de Custos, São Paulo, junho de 1999.

FERREIRA, Tadeu. Temas Contábeis em Destaque Passivo Ambiental. São Paulo: Atlas, 2000.

FOLHA DE SÃO PAULO. Respeito ao Meio Ambiente dá lucro. Caderno Sua Vez, 22 de agosto de 1999.

IBRACON. Normas e procedimentos de auditoria. NPA 11 - Balanço e Ecologia.1996.

INTERNATIONAL FEDERATION OF ACCOUNTANTS (IFAC). Environmental management in 
organization: the role of management accounting. New York, march 1998.

IUDíCIBUS, Sérgio \& Outros. Manual de Contabilidade das Sociedades por Ações - Aplicável também às demais sociedades. $4^{\mathrm{a}}$ ed. rev. at., São Paulo: Atlas, 1995.

IUDÍCIBUS, Sérgio de \& MARION, José Carlos. Introdução à Teoria da Contabilidade. $2^{\mathrm{a}}$ ed., São Paulo: Atlas, 2000.

KROETZ, César Eduardo S. Balanço Social: uma demonstração da responsabilidade social, ecológica e gestorial das entidades. Revista Brasileira de Contabilidade. Brasília: CFC, a.27, n. 113, set/ out. 1998.

LISBOA, Lázaro Plácido \& RIBEIRO, Maisa de Souza, Balanço Social. Revista Brasileira de Contabilidade. Brasília: CFC, ano 28, no 115, jan/fev, , 1999.

MARCOVITCH, Jacques. Modernidade e ambiente. Folha de São Paulo, Opinião, 14 de jul. 1999.

MARTINS, Eliseu \& DE LUCA, Márcia M. Mendes. Ecologia via Contabilidade. Revista Brasileira de Contabilidade. Brasília: CFC, ano 23, nํㅛ 86, março 1994.

MARTINS, Eliseu \& RIBEIRO, Maisa de Souza. $A$ in formação como instrumento de contribuição da contabilidade para a compatibilização do desenvolvimento econômico e a preservação do meio ambiente. IBRACON, boletim 208, São Paulo, 1995.

NOVAES, Washington. As contas do outro lado. Espaço Aberto, O Estado de São Paulo, 27 de abril de 2001.
RIBEIRO, Maísa de Souza. Contabilidade e Meio Ambiente. Dissertação (mestrado). FEA/USP, 1992.

RIBEIRO, Maísa de Souza \& MARTINS, Eliseu. Ações das empresas para a preservação do meio ambiente. Abrasca, boletim 415, São Paulo, 1998.

RIBEIRO, Maísa de Souza. Tratamento contábil dos gastos de natureza ambiental pelo custeio por atividades. Revista de Contabilidade do CRC-SP, ano 3, no 7, março de 1999.

RIBEIRO, Maísa de Souza. Custeio das atividades da natureza ambiental. Tese (doutorado). FEA/USP, 1998.

SANCHES, Carmen Silvia. Evolução das práticas ambientais em empresas industriais: um modelo genérico. In Anais IV Encontro Nacional sobre Gestão Empresarial e Meio Ambiente, São Paulo, nov. 1997.

SARNEY FILHO, José. Educação ambiental no Brasil. Folha de São Paulo, Opinião, 10 de maio 1999.

TINOCO, João Eduardo Prudência. Ecologia, Meio Ambiente e Contabilidade. Revista Brasileira de Contabilidade. Brasília: CFC, ano 23, nº 89, nov. 1994.

TRIPOLI, Ricardo. Ecologia urbana. Folha de São Paulo, Opinião, 29 de julho de 1999.

U.S. ENVIRONMENTAL PROTECTION AGENCY (EPA). Introduction to environmental accounting as a business management tool: key concepts and terms. Washington, june 1995. 